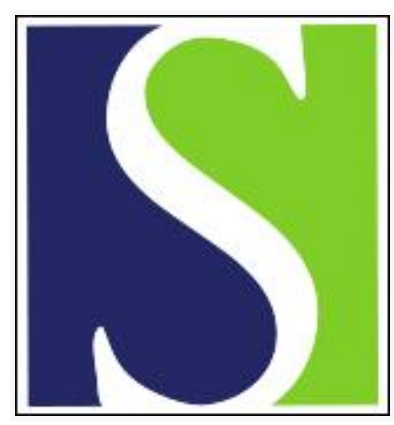

Scand J Work Environ Health 2008;34(4):316-321

https://doi.org/10.5271/sjweh.1270

Published online: 22 Sep 2008, Issue date: Aug 2008

Meteorological conditions and the diagnosis of occupationally related contact sensitizations

by Hegewald J, Uter W, Kränke B, Schnuch A, Pfahlberg A, Gefeller O

Affiliation: Department of Medical Informatics, Biometry and Epidemiology, Friedrich-Alexander University Erlangen-Nürnberg, Waldstr. 6, D-91054 Erlangen, Germany. janice.hegewald@imbe.med.uni-erlangen.de

Key terms: allergic contact; clinical epidemiology; contact sensitization; dermatitis; diagnosis; meteorological conditions; occupational dermatitis; patch testing; weather

This article in PubMed: www.ncbi.nlm.nih.gov/pubmed/18815718 


\title{
Meteorological conditions and the diagnosis of occupationally related contact sensitizations
}

\author{
by Janice Hegewald, PhD, ${ }^{1}$ Wolfgang Uter, MD, ${ }^{1}$ Birger Kränke, MD, ${ }^{2}$ Axel Schnuch, MD, ${ }^{3}$ \\ Annette Pfahlberg, PhD, ${ }^{1}$ Olaf Gefeller, PhD ${ }^{1}$
}

\begin{abstract}
Hegewald J, Uter W, Kränke B, Schnuch A, Pfahlberg A, Gefeller 0. Meteorological conditions and the diagnosis of occupationally related contact sensitizations. Scand J Work Environ Health 2008;34(4):316-321.
\end{abstract}

\begin{abstract}
Objectives An accurate diagnosis of (occupational) contact sensitization by patch testing is a prerequisite for efficient preventive management. However, previously observed seasonal fluctuations in patch-test reactions indicate some influence of meteorological conditions. The present analysis aims at quantifying the possible impact of temperature and humidity on patch-test reactions to occupationally related allergens.

Methods Clinical data from 61780 patients tested with standard series allergens potentially related to occupational exposure from 1993 through 2001 were collected by a contact sensitization surveillance network. The association between the patch-test results and meteorological data (air temperature and humidity) collected at the time and the approximate location of the testing was analyzed in a multinomial logistic regression analysis.

Results For three allergens (a dye and two biocides), the odds of irritant or doubtful allergic reactions increased during cold and arid conditions. Two of them ( $p$-phenylenediamine and formaldehyde) also showed an association between weak positive allergic reactions and such weather. In contrast, reactions to various adhesive, plastic, and rubber-related allergens were not associated with weather conditions.

Conclusions An overall increase in skin irritation, brought on by cold and dry conditions, may instigate an increase in positive reactions by leading doubtful allergic reactions to be (falsely) categorized as allergic for at least two of the considered allergens. For the most part, however, weather conditions were not associated with reactions to occupational allergens. Thus the validity of patch testing does not largely seem to be compromised by ambient meteorological conditions.
\end{abstract}

Key terms allergic contact; dermatitis; clinical epidemiology; occupational dermatitis; patch testing; weather.

Occupational skin disease is one of the most common and costliest categories of occupationally acquired diseases due to lost productivity, costs for workers' treatment and compensation, and possibly retraining. Contact dermatitis with an allergic or irritant etiology comprises a large proportion of the reported cases of occupational skin disease, such as $80 \%$ of the cases registered in the United Kingdom (1). Annual incidences ranging from 0.5 to 1.9 per 1000 employees have been reported (2). Regarding the role of contact sensitization (ie, allergic contact dermatitis), a German population-based study found that $52 \%$ of the persons with occupational skin disease tested positive for an occupationally relevant allergen (3).
Contact sensitizations usually persist for a long time, possibly as long as life. Given the importance of avoiding allergens to prevent relapses of allergic contact dermatitis, it can be difficult to continue working in the profession that led to sensitization in the first place. Whether for the identification of targeted secondary preventive measures or for an adequate assessment of occupational inability (4), the identification of occupational sensitizations by means of a standardized patch test (5) must be timely (6). However, the patch test has limited reproducibility as a standard diagnostic procedure (7), this limitation may at least partly be due to meteorological conditions, in view of the seasonal fluctuations of patch-test results previously observed

1 Department of Medical Informatics, Biometry and Epidemiology, Friedrich-Alexander University Erlangen-Nürnberg, Germany.

2 Department of Dermatology and Veneorology, Medical University of Graz, Austria.

3 Information Network of Departments of Dermatology (IVDK) at the Georg August University, Göttingen, Germany.

Correspondence to: Dr Wolfgang Uter, Department of Medical Informatics, Biometry and Epidemiology, Friedrich-Alexander University Erlangen-Nürnberg, Waldstr. 6, D-91054 Erlangen, Germany. [E-mail: wolfgang.uter@imbe.med.uni-erlangen. de] 
(8-11). In particular, the increase in skin irritability observed during cold or dry conditions demonstrates the susceptibility of the skin to environmental conditions (12-14). Striving to reconcile previous, partly conflicting evidence and ultimately to improve patch-test standardization, we set out to examine the extent to which the outside air temperature and humidity at the time of a patch-test application may affect patch-test reactions to occupational allergens.

\section{Study population and methods}

A diagnostic patch test was performed on patients with suspected contact sensitization at 28 centers of the Information Network of Departments of Dermatology [Informationsverbund Dermatologischer Kliniken (IVDK), www.ivdk.org] in Austria and Germany with standard series of the German Contact Dermatitis Research Group (DKG). National or international standard series generally include a set of allergens recognized as the most important or most common. Altogether 61780 patients were tested with at least 1 of 10 allergens frequently associated with occupational exposures during 1993 through 2001. The allergens examined included $p$-phenylenediamine (PPD), formaldehyde, methylchloroisothiazolinone-methylisothiazolinone (MCI-MI), thiuram mix, colophony, N-isopropyl N'phenyl-p-phenylenediamine (IPPD), epoxy resin of the BADGE type, $p$-tert-butylphenol formaldehyde resin ( $p$ TBFR), zinc diethyldithiocarbamate (ZDEC), and mercaptobenzothiazole (MBT); for the test concentrations and vehicles see table 1 . All of the received patient data were anonymous and included both patch-test results and information regarding important items of the patients' histories. Patch tests were applied to the skin for 1 or 2 days. Patch-test readings were taken on the third day after the initial test application and classified on morphological grounds according to international guidelines (5). Of the 61780 patients tested with the occupational allergens, $63 \%$ were female. The median (and mean) age of the patients was 46 years with an interquartile range of 31 to 59 years, and $21 \%$ of the patients had a history of atopic dermatitis. The number of patients tested with the individual allergens and the frequency of reactions are listed in table 1. Patch tests were applied for 48 hours to $62 \%$ of all of the patients and for 24 hours for the rest. Fewer patients were tested with MBT because it was omitted from the official DKG standard series during a considerable proportion of the study period (July 1993-June 2000), although some departments continued to include it in their standard allergy screening panels during these years.

Meteorological data in terms of the daily mean values of temperature and relative humidity were obtained from the Austrian Central Institute for Meteorology and Geodynamics (Zentralanstalt für Meteorologie und Geodynamic, Vienna, Austria) and the German Meteorological Service (Deutscher Wetterdienst, Offenbach and Freiburg, Germany). The weather stations were located within 30 kilometers of the dermatology departments. According to previous research, absolute humidity and vapor pressure are preferable over relative humidity for the analysis in terms of an observed association with irritant skin damage (13-15). Therefore, the values for absolute humidity and vapor pressure were derived from the temperature and relative humidity values for the analysis with published formulas $(16,17)$. Due to the similarity between the results of the absolute humidity and the vapor pressure analyses, only the results of the absolute humidity models are presented in this publication. The overall average temperature during the study period at the study locations was $9.9^{\circ} \mathrm{C}$ (median $10.1^{\circ} \mathrm{C}$ ) with a range of $-19.0^{\circ} \mathrm{C}$ to $30.3^{\circ} \mathrm{C}$. Concerning humidity, the mean absolute humidity was $7.6 \mathrm{~g} / \mathrm{m}^{3}$ (median $7.3 \mathrm{~g} / \mathrm{m}^{3}$ ), ranging from 0.96 to $19.6 \mathrm{~g} / \mathrm{m}^{3}$. In the colder 6 months of the year (October through March), the mean temperature and absolute humidity were $4.5^{\circ} \mathrm{C}$ and $5.66 \mathrm{~g} / \mathrm{m}^{3}$, respectively, compared with $15.2^{\circ} \mathrm{C}$ and $9.55 \mathrm{~g} / \mathrm{m}^{3}$, respectively, in the warmer months (April through September).

Table 1. Numbers of patients tested and the resulting test reactions. ${ }^{\text {a }}(\mathrm{IR} /$ ? = irritant or doubtful reaction, $+=$ weak reaction, $++/+++=$ strong reaction, $\mathrm{PPD}=p$-phenylenediamine, $\mathrm{MCl}-\mathrm{MI}$ $=$ methylchloroisothiazolinone-methylisothiazolinone, $p$ TBFR = $p$-tert-butylphenol formaldehyde resin, IPPD = N-isopropyl N'phenyl- $p$-phenylenediamine, MBT = mercaptobenzothiazole, ZDEC = zinc diethyldithiocarbamate)

\begin{tabular}{|c|c|c|c|c|c|c|c|c|}
\hline \multirow[t]{3}{*}{ Allergen ${ }^{a}$} & \multirow{3}{*}{$\begin{array}{c}\text { Test } \\
\text { concen- } \\
\text { tration } \\
(\%)\end{array}$} & \multirow{3}{*}{$\begin{array}{l}\text { Patients } \\
\text { tested } \\
\text { (N) }\end{array}$} & \multicolumn{6}{|c|}{ Test reaction } \\
\hline & & & \multicolumn{2}{|c|}{$\mathrm{IR} / ?$} & \multicolumn{2}{|c|}{+} & \multicolumn{2}{|c|}{ ++/+++ } \\
\hline & & & N & $\%$ & N & $\%$ & N & $\%$ \\
\hline \multicolumn{9}{|l|}{ Dye } \\
\hline PPD & 1 & 61132 & 913 & 1.5 & 1605 & 2.6 & 1184 & 1.9 \\
\hline \multicolumn{9}{|l|}{ Biocides } \\
\hline Formaldehyde & e 1 & 61217 & 900 & 1.5 & 890 & 1.5 & 285 & 0.5 \\
\hline MCl-MI & 0.01 & 59999 & 529 & 0.9 & 993 & 1.7 & 464 & 0.8 \\
\hline \multicolumn{9}{|c|}{ Adhesives (plastic materials) } \\
\hline Colophony & 20 & 61171 & 639 & 1.0 & 1374 & 2.2 & 1094 & 1.8 \\
\hline Epoxy resin & 1 & 61204 & 381 & 0.6 & 372 & 0.6 & 343 & 0.6 \\
\hline pTBFR & 1 & 61176 & 373 & 0.6 & 431 & 0.7 & 216 & 0.4 \\
\hline \multicolumn{9}{|c|}{ Rubber constituents } \\
\hline IPPD & 0.1 & 59061 & 432 & 0.7 & 287 & 0.5 & 244 & 0.4 \\
\hline MBT & 2 & 29885 & 158 & 0.5 & 143 & 0.5 & 127 & 0.4 \\
\hline Thiuram mix & 1 & 61154 & 504 & 0.8 & 958 & 1.6 & 652 & 1.1 \\
\hline ZDEC & 1 & 55982 & 196 & 0.4 & 187 & 0.3 & 109 & 0.2 \\
\hline
\end{tabular}

a All of the allergens were diluted in petrolatum, except formaldehyde and $\mathrm{MCl}-\mathrm{MI}$, for which water was used. 
Moving averages of the meteorological variables, including the day of the patch-test application and the 2 days preceding the application, were calculated and matched appropriately to the corresponding dates of the patch-test application. Multinomial logistic regression was used to examine the relationship between the temperature and humidity with the patch-test results. The test readings of the individual allergens served as the dependent variable, the negative reactions being used as the reference for irritant or doubtful ("IR/?"), weak allergic ("+"), and strong allergic ("++/+++") reactions, respectively. We divided the temperature and humidity values into four categories at their quartiles and examined the variables in separate models. All of the models also included the variables age, gender, atopic dermatitis, and duration of the patch test ( 1 or 2 days) as potential confounders. The statistical analysis was conducted with SAS, version 9 (Cary, NC, USA).

\section{Results}

As an initial examination of the potential association between the meteorological factors and the reaction categories, the mean values and 95\% confidence intervals ( $95 \% \mathrm{CI}$ ) of the temperature on the day of the patch-test application were calculated, stratified according to the resulting patch-test reaction category (figure 1). For
PPD, formaldehyde, MCI-MI, colophony, epoxy resin, and thiuram mix, patch tests resulting in irritant and doubtful reactions had been performed under slightly lower mean outdoor temperatures than the tests resulting in weak and strong positive reactions. Moreover, with the exception of epoxy resin, a slight trend towards the temperatures peaking with strong allergic reactions could be noted. However, the differences in the means were small. No consistent pattern could be discerned for the remaining allergens.

The adjusted logistic regression analysis incorporated temperature and absolute humidity into separate models. Temperature yielded risk estimates very similar to those obtained when absolute humidity was used, and this finding is very plausible in view of the strong correlation between these two meteorological variables (the colder the air, the less its water-holding capacity). Hence only the results regarding absolute humidity are presented in table 2. PPD, MCI-MI, and particularly formaldehyde were the only occupational allergens demonstrating fairly consistent positive associations between irritant and doubtful reactions and dry or cold outdoor weather conditions. In addition, PPD and formaldehyde also showed such an association between weak allergic reactions and weather conditions. The patch-test reactions of plastic-, adhesive-, and rubber-related allergens were not consistently dependent on weather conditions. MBT did show a weak trend towards reduced odds of irritant or doubtful reactions with decreasing absolute humidity; contrary to the aforementioned pattern,

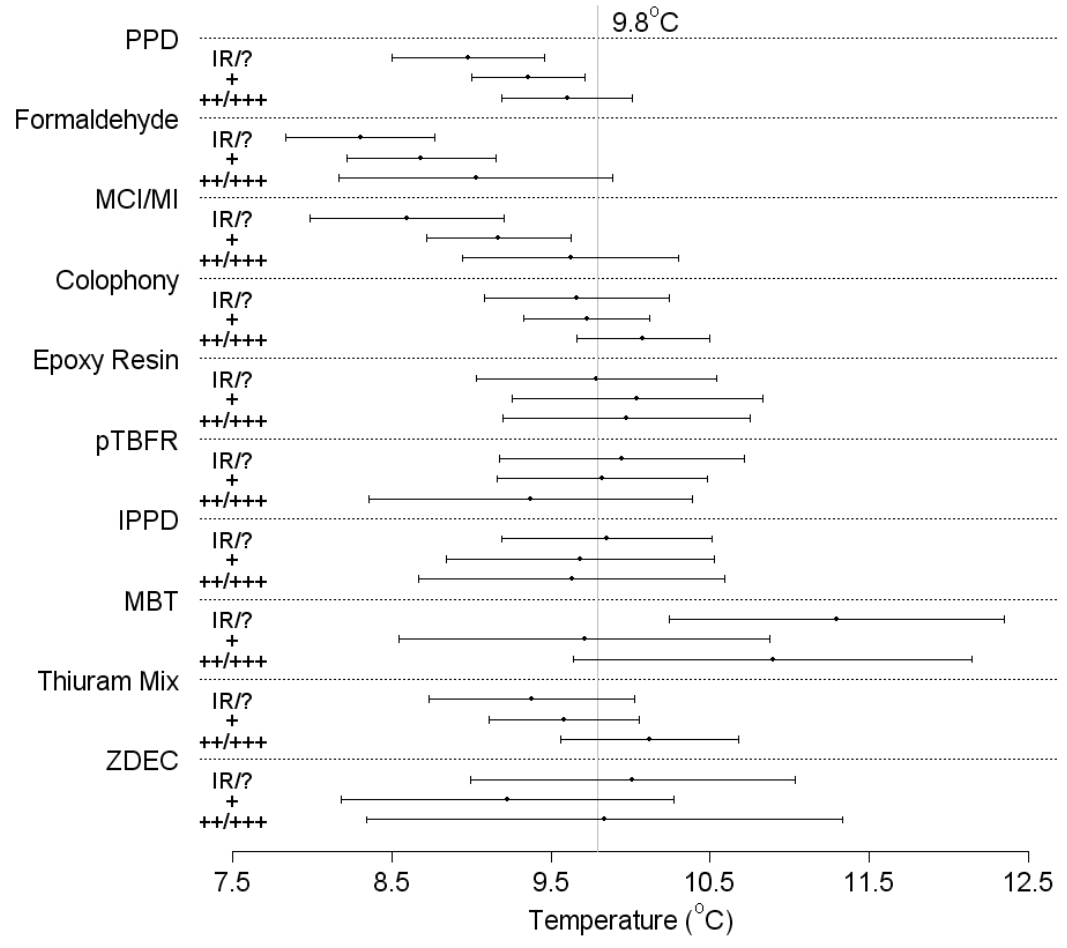

Figure 1. Means and $95 \%$ confidence intervals of the temperatures on the day of the patch-test application, stratified by the resulting test reactions. The overall mean temperature observed on the days of the patch-test application was $9.8^{\circ} \mathrm{C}$. $(\mathrm{PPD}=p$-phenylenediamine, $\mathrm{IR} /$ ? = irritant or doubtful reaction, $+=$ weak reaction, $++/+++=$ strong reaction, $\mathrm{MCl}-\mathrm{MI}=$ methylchloroisothiazolinone-methylisothiazolinone, $p$ TBFR $=p$-tert-butylphenol formaldehyde resin, IPPD $=$ N-isopropyl N'-phenyl- $p$-phenylenediamine, $\mathrm{MBT}=$ mercaptobenzothiazole, $\mathrm{ZDEC}=$ zinc diethyldithiocarbamate) 
however, only the estimate of the odds ratio of the lowest category was significant.

\section{Discussion}

Ensuring the validity of diagnoses of occupational contact sensitization is essential, due to their important individual, legal, and financial consequences. While the standardized patch-test procedure is still the best available method for identifying (occupational) contact allergies, the biological nature of the procedure leaves it more or less susceptible to external factors, such as outdoor meteorological conditions, as shown by the presented analysis. Therefore, understanding if and how patch-test reactions can be influenced by weather conditions could further improve the diagnostic performance of the test. A consideration of ambient conditions could, for instance, prompt an adjustment of the interpretation of reactions, re-testing, or confirmation with validation procedures such as repeated open-application testing (5).

Similar to previous studies on the seasonality of patch-test reactions, which report inconsistent results of cumulated patch-test reactions or distinct seasonal patterns for individually examined allergens, we observed no uniform or general relation between reactions to the set of considered occupational allergens and weather conditions. Only a few allergens with weather dependencies were revealed, namely, the one dye component (PPD) and the two biocides (formaldehyde and MCI-MI). The latter two compounds are also the only two allergens in the standard series tested in an aqueous solution. Possibly, the use of water as the vehicle, or the hydrophilic nature of the allergens, contributes to the irritancy of these two test preparations. Mostly, increased odds of nonallergic reactions coincided with colder temperatures and lower humidity, while relations between weak allergic reactions and weather conditions were less evident, and strong allergic reactions were unrelated to the weather.

Most of the examined occupational allergens showed no consistent association between the weather and either nonallergic or allergic patch-test reactions. This inconsistency applied to all of the allergens found in the plastic-adhesives family (ie, epoxy resin, colophony, or $p$ TBFR) and the allergens used to accelerate the vulcanization of rubber or incorporated into rubber products for durability. Although at least the rubber allergens can be regarded as marginal irritants (18), the way these allergens irritate may fundamentally differ from the mechanisms involved in weather-related irritation by patch-test allergens (such as formaldehyde and MCI-MI) or frank irritants such as sodium lauryl sulfate (SLS). Supporting the notion of such different modes of irritation, Agner \&
Table 2. Odds ratios (OR) and 95\% confidence intervals (95\% $\mathrm{CI})$ for the test-patch reaction $(\mathrm{IR} /$ ? , + or $++/++)$ of potentially occupational contact allergens according to categories of absolute humidity. $(\mathrm{PPD}=p$-phenylenediamine, $\mathrm{IR} / \mathrm{?}=$ irritant or doubtful reaction, $+=$ weak reaction, $++/+++=$ strong reaction, $\mathrm{MCl} / \mathrm{MI}=$ methylchloroisothiazolinone-methylisothiazolinone, $p$ TBFR $=p$ tert-butylphenol formaldehyde resin, IPPD = N-isopropyl N'-phenyl- $p$-phenylenediamine, MBT = mercaptobenzothiazole, ZDEC = zinc diethyldithiocarbamate)

\begin{tabular}{|c|c|c|c|c|c|c|}
\hline \multirow{3}{*}{$\begin{array}{l}\text { Potential } \\
\text { occupational } \\
\text { contact } \\
\text { allergen }\end{array}$} & \multicolumn{6}{|c|}{ Absolute humidity $\left(\mathrm{g} / \mathrm{m}^{3}\right)$, reference $>10$} \\
\hline & \multicolumn{2}{|r|}{$\leq 5$} & \multicolumn{2}{|r|}{$6-7$} & \multicolumn{2}{|c|}{$8-10$} \\
\hline & $\mathrm{OR}$ & $95 \% \mathrm{Cl}$ & $\mathrm{OR}$ & $95 \% \mathrm{Cl}$ & $\mathrm{OR}$ & $95 \% \mathrm{Cl}$ \\
\hline \multicolumn{7}{|l|}{ PPD } \\
\hline $\mathrm{IR} / ?$ & 1.28 & $1.05-1.57$ & 1.33 & $1.10-1.61$ & 1.08 & $0.89-1.32$ \\
\hline+ & 1.11 & $0.95-1.29$ & 1.28 & $1.10-1.48$ & 1.22 & $1.05-1.40$ \\
\hline$++/++$ & 0.96 & $0.80-1.14$ & 1.15 & $0.98-1.36$ & 1.04 & $0.88-1.22$ \\
\hline \multicolumn{7}{|c|}{ Formaldehyde } \\
\hline $\mathrm{IR} /$ ? & 1.69 & $1.36-2.09$ & 1.70 & $1.38-2.10$ & 1.48 & $1.20-1.82$ \\
\hline+ & 1.69 & $1.37-2.08$ & 1.50 & $1.22-1.84$ & 1.33 & $1.08-1.64$ \\
\hline$++/+++$ & 1.37 & $0.96-1.96$ & 1.38 & $0.97-1.95$ & 1.12 & $0.78-1.60$ \\
\hline \multicolumn{7}{|l|}{$\mathrm{MCl} / \mathrm{Ml}$} \\
\hline $\mathrm{IR} / ?$ & 1.45 & $1.12-1.88$ & 1.33 & $1.03-1.72$ & 1.05 & $0.81-1.37$ \\
\hline+ & 1.20 & $0.98-1.45$ & 1.21 & 1.01 & 1.15 & $0.95-1.38$ \\
\hline$++/++$ & 1.11 & $0.83-1.47$ & 1.23 & $0.94-1.61$ & 1.17 & $0.89-1.53$ \\
\hline \multicolumn{7}{|l|}{ Colophony } \\
\hline $\mathrm{IR} / ?$ & 0.88 & $0.70-1.11$ & 0.92 & $0.74-1.14$ & 0.75 & $0.60-0.94$ \\
\hline+ & 1.04 & 0.89 & 0.98 & 0.84 & 1.03 & $0.89-1.20$ \\
\hline$++/+++$ & 0.92 & $0.76-1.11$ & 1.08 & $0.91-1.29$ & 1.10 & $0.93-1.31$ \\
\hline \multicolumn{7}{|l|}{ Epoxy resin } \\
\hline $\mathrm{IR} /$ ? & 1.06 & $0.78-1.43$ & 0.91 & $0.67-1.22$ & 1.15 & $0.87-1.52$ \\
\hline+ & 0.93 & $0.69-1.27$ & 1.05 & $0.79-1.39$ & 0.93 & $0.69-1.24$ \\
\hline$++/+++$ & 0.86 & $0.63-1.17$ & 0.89 & $0.66-1.20$ & 0.84 & $0.62-1.13$ \\
\hline \multicolumn{7}{|l|}{ pTBFR } \\
\hline IR/? & 0.98 & $0.73-1.33$ & 0.86 & $0.64-1.16$ & 0.99 & $0.75-1.32$ \\
\hline+ & 0.97 & $0.73-1.30$ & 1.20 & $0.91-1.56$ & 0.99 & $0.75-1.30$ \\
\hline$++/+++$ & 1.27 & $0.86-1.88$ & 0.87 & $0.58-1.31$ & 1.07 & $0.73-1.57$ \\
\hline \multicolumn{7}{|l|}{ IPPD } \\
\hline $\mathrm{IR} /$ ? & 1.03 & 0.77 & 1.07 & 0.8 & 1.09 & 0.8 \\
\hline+ & 1.11 & $0.78-1.59$ & 1.16 & $0.83-1.63$ & 1.12 & $0.80-1.57$ \\
\hline$++/+++$ & 1.13 & $0.78-1.64$ & 0.85 & $0.58-1.24$ & 1.08 & $0.76-1.54$ \\
\hline \multicolumn{7}{|l|}{ MBT } \\
\hline $\mathrm{IR} / ?$ & 0.55 & $0.33-0.93$ & 0.78 & $0.50-1.21$ & 0.99 & $0.67-1.48$ \\
\hline+ & 1.17 & $0.71-1.92$ & 0.98 & $0.60-1.60$ & 1.13 & $0.71-1.80$ \\
\hline$++/+++$ & 0.71 & $0.41-1.23$ & 0.77 & $0.47-1.27$ & 1.01 & $0.64-1.60$ \\
\hline \multicolumn{7}{|l|}{ Thiuram mix } \\
\hline $\mathrm{IR} /$ ? & 1.04 & 0.80 & 0.95 & $0.73-1.23$ & 1.17 & $0.91-1.49$ \\
\hline+ & 1.04 & $0.86-1.26$ & 1.07 & $0.88-1.28$ & 1.05 & $0.87-1.26$ \\
\hline$++/+++$ & 0.86 & $0.68-1.09$ & 1.00 & $0.80-1.24$ & 1.04 & $0.84-1.29$ \\
\hline \multicolumn{7}{|l|}{ ZDEC } \\
\hline $\mathrm{IR} / ?$ & 1.04 & $0.66-1.64$ & 1.21 & $0.79-1.84$ & 1.44 & $0.97-2.16$ \\
\hline+ & 1.22 & $0.78-1.91$ & 1.27 & $0.83-1.95$ & 1.20 & $0.79-1.84$ \\
\hline$++/+++$ & 0.93 & $0.53-1.62$ & 1.03 & $0.61-1.72$ & 0.80 & $0.47-1.38$ \\
\hline
\end{tabular}

Serup (12) demonstrated that reactions to SLS, a model irritant that injures the skin's barrier function, fluctuate seasonally, while reactions to the irritant nonanonic acid (which has little effect on barrier function) showed no seasonal pattern. 
The fact that mostly irritant reactions are related to weather further supports the notion that winter conditions may be making the skin susceptible to irritant or doubtful patch-test reactions, in line with previous evidence (12-14). The increase in weak allergic reactions partly paralleling the increase in irritant or doubtful reactions could indicate an amplified morphological appearance of the latter reactions, which led to a morphological categorization of "weak positive" (false positive).

One strength of this study was the level of accuracy achieved for the exposure data. Never before have actual meteorological data, rather than its surrogates, season, or the month of the year, been combined with patch-test data, except in our own previous pilot study (11). Obviously, it could still be argued that the averaged ambient (outdoor) values may not exactly represent a person's exposure. However, it would probably not be feasible to ascertain exposure on an individual level. Nevertheless, several factors redeem the use of the outdoor meteorological measurements, (i) air conditioning was not very common in Austria and Germany during the study period, (ii) indoor absolute humidity is thus correlated with outdoor values even in winter (19), and (iii) there is evidence that skin locations typically covered with clothing (at least in winter) are nevertheless susceptible to temperature, humidity, and seasonal variation (12). Ultraviolet exposure, which could potentially have suppressed patch-test reactions, was not thought to have greatly influenced the results, as testing patients with recent ultraviolet exposure goes against international patch-testing guidelines (5) and a thorough Belgian study found no evidence of a correlation between ultraviolet intensity prior to patch testing and subsequent reactions (20).

In conclusion, due to the potential repercussion of invalid patch-test readings, particularly in the (medicolegal) context of occupational contact dermatitis, an improved understanding of the relationship between patch-test reactions and meteorological conditions helps ensure that this diagnostic method is as accurate as possible. Reassuringly, patch tests to most occupational allergens, especially allergens found in resins and adhesives, and those used in rubber are not significantly influenced by outdoor conditions around the time of the testing. In contrast, irritant or doubtful and weak positive patch-test reactions to a few occupationally related allergens are associated with meteorological conditions, namely, PPD, formaldehyde and MCI-MI. While the increased occurrence of irritant or doubtful reactions is no concern, as they are normally not regarded as allergic, the potential of "weak positive" patch-test reactions to be false positive is a greater concern. In cases of uncertainty, retesting and confirmatory tests (5) can be used to validate initial results obtained during extreme winter conditions.

\section{Acknowledgments}

The Adolf-Rohrschneider Trust Foundation of the Friedrich-Alexander University Erlangen-Nürnberg, the Bavarian State Grant, and the Society for the Advancement of Biostatistics and Epidemiology, Erlangen-Nürnberg helped fund this project.

We would like to acknowledge the Central Institute for Meteorology and Geodynamics (Vienna, Austria) and the German Weather Service (Offenbach, Germany) for providing weather data and the following members of the Information Network of Departments of Dermatology for contributing clinical data to this analysis (in alphabetical order): Aachen (H Dickel, S. Erdmann), Berlin Charité (B Laubstein, T Zuberbier), Berlin UKRV ( $\mathrm{J}$ Grabbe, T Zuberbier), Berlin B-Frank (B Tebbe, R Treudler), Dortmund (PJ Frosch, B Pilz, C Pirker, R Herbst), Dresden (G Richter, R Aschoff), Erlangen (K-P Peters, TL Diepgen, M Fartasch, M Hertl, V Mahler), Essen (H-M Ockenfels, U Hillen), Göttingen (Th Fuchs, J Geier), Graz (W Aberer, B Kränke), Halle (G Gaber, D Lübbe), Hamburg (M Kiehn, D Vieluf, R. Weßbecher), Heidelberg (A Schulze-Dirks, M Hartmann, U Jappe), Homburg and Saar (FA Bahmer, P Koch), Jena (M Gebhardt, A Bauer, W Wigger-Alberti, M Kaatz, S Schliemann-Willers), Kiel (J Brasch), Lübeck (KP Wilhelm, J Kreusch, J Grabbe), Mainz (D Becker), Marburg (I Effendy, H Löffler), München LMU (F Enders, F Rueff, B Przybilla), München TU (J Rakoski), München-Schwabing (M Agathos), Nürnberg (I Müller), Osnabrück [W Uter, SM John, HJ Schwanitz (deceased), N Schürer], Tübingen (G Lischka), Ulm [H Gall (deceased), P Gottlöber, G Staib], Wuppertal (O Mainusch, J Raguz).

\section{References}

1. Shum KW, Meyer JD, Chen Y, Cherry N, Gawkrodger DJ. Occupational contact dermatitis to nickel: experience of the British dermatologists (EPIDERM) and occupational physicians (OPRA) surveillance schemes. Occup Environ Med. 2003;60:954-7.

2. Diepgen TL. Occupational skin-disease data in Europe. Int Arch Occup Environ Health. 2003;76:331-8.

3. Dickel H, Kuss O, Blesius CR, Schmidt A, Diepgen TL. Occupational skin diseases in Northern Bavaria between 1990 and 1999: a population-based study. Br J Dermatol. 2001;145:45362.

4. Frosch PJ, Aberer W, August PJ, Adams RM, Agner T, Beck $\mathrm{MH}$, et al. International comparison of legal aspects of worker compensation for occupational contact dermatitis. In: Frosch PJ, Menné T, Lepoittevin JP, editors. Contact dermatitis. Berlin: Springer; 2006. p 875-91.

5. Wahlberg JE, Lindberg M. Patch testing. In: Frosch PJ, Menné T, Lepoittevin JP, editors. Contact dermatitis. Berlin: Springer; 
2006. p 365-90.

6. Lips R, Rast H, Elsner P. Outcome of job change in patients with occupational chromate dermatitis. Contact Dermatitis. 1996;34:268-71.

7. Uter W, Pfahlberg A, Brasch J. Zur Reproduzierbarkeit der Epikutantestung-Die Bewertung der Konkordanz bei synchroner Applikation [Reproducibility of patch testing-an analysis of concordance with synchronous application]. Allergologie. 2002;25:415-9.

8. Edman B. Seasonal influence on patch test results. Contact Dermatitis. 1989;20:226.

9. Hjorth N. Seasonal variation in contact dermatitis. Acta Dermatol Venereol. 1967;47:409-18.

10. Kränke B, Aberer W. Seasonal influence on patch test results in Central Europe. Contact Dermatitis. 1996;34:215-6.

11. Uter W, Geier J, Land M, Pfahlberg A, Gefeller O, Schnuch A. Another look at seasonal variation in patch test results: a multifactorial analysis of surveillance data of the IVDK. Contact Dermatitis. 2001;44(3):146-52.

12. Agner T, Serup J. Seasonal variation of skin resistance to irritants. Br J Dermatol. 1989;121:323-8.

13. Löffler H, Happle R. Influence of climatic conditions on the irritant patch test with sodium lauryl sulphate. Acta Derm Venereol. 2003;83:338-41.

14. Uter W, Gefeller O, Schwanitz HJ. An epidemiological study on the influence of Season (cold and dry air) on the occur- rence of irritant skin changes of the hands. Br J Dermatol. 1998;138:266-72.

15. Cooper MD, Jardine H, Ferguson J. Seasonal influence on the occurrence of dry flaking facial skin. In: Marks R, Plewig G. The environmental threat to the skin. London: M Dunitz; 1992. p 159-64.

16. Schubert A. Aspirations-Psychrometertafel des Deutschen Wetterdienstes. [Aspiration psychrometer tables of the German Meteorological Service]. Braunschweig (Germany): F Vieweg; 1976.

17. Zmarsly E, Kuttler W, Pethe H. Meteorologisch-klimatologisches Grundwissen [Meteorological-climatological fundamentals]. 2nd Ed. Stuttgart (Germany): Eugen Ulmer; 2002.

18. Cockayne SE, Gawkrodger DJ. Angry back syndrome is often due to marginal irritants: a study of 17 cases seen over 4 years. Contact Dermatitis. 2000;43:280-2.

19. Emenius G, Svartengren M, Korsgaard J, Nordvall L, Pershagen G, Wickman M. Building characteristics, indoor air quality and recurrent wheezing in very young children (BAMSE). Indoor Air. 2004;14:34-42.

20. Dooms Goossens A, Lesaffre E, Heidbüchel M, Dooms M, Degreef H. UV sunlight and patch test reactions in humans. Contact Dermatitis. 1988;19:36-42.

Received for publication: 10 March 2008 